Goran Stanivuković

\title{
ŠEKSPIR I SVAKODNEVNOST
}

U radu se pokazuje kako se književno-teorijski i kritički pojam svakodnevnosti može primeniti na tumačenje Sekspirovih drama iz ranog perioda njegovog stvaralaštva. Svakodnevnost predstavlja stilski otklon od pravila drame, naročito od uzvišene i učene retorike raskošnog stila koja dominira dramama iz 90-ih godina XVI veka. Šekspir koristi svakodnevnost pored ostalog i da bi tragediju prilagodio predstavljanju u javnim pozorištima u Londonu.

Ključne reči: svakodnevnost, tragedija, komedija, javno pozorište, prva polovina 90-ih godina XVI veka.

U svojoj poslednjoj knjizi, Šekspirova dramaturgija, Veselin Kostić ukratko piše o nekoliko vrsta početaka Šekspirovih drama i jednu takvu vrstu naziva ,paralelnim” početkom u kojem ,,radnja počinje da teče u registru običnog govora, kao da je u pitanju neko neposredno zbivanje koje je do tog trenutka bilo izvan vidnog i slušnog polja gledalaca, a sada ulazi u delokrug njihove pažnje” (2010: 87). Kao primer, Kostić navodi prvu scenu iz tragedije Kralj Lir, ,,koja počinje u ključu svakodnevnog razgovora između Kenta i Glostera." (2010: 87) Taj početak glasi ovako:

KenT: Mislio sam da kralj više voli vojvodu od Olbanija nego vojvodu od Konvala.

GLoster: Tako nam je uvek izgledalo; ali sad, pri podeli kraljevine, ne vidi se koga vojvodu on najviše ceni, jer su delovi tako ravnomerni da se njih dvojica, ni s najpažljivijim ispitivanjima ne bi mogli odlučiti koji da izaberu. (1.1.. ${ }^{1}$

1 Prevod Živojin Simić i Sima Pandurović. U originalu ovaj razgovor napisan prozom glasi ovako: 
Svakodnevnost ovog razgovora je pre svega u njegovom stilskom izrazu. Dvojica vojvoda ne govore raskošnim retoričkim jezikom, što bi odgovaralo njihovom društvenom statusu. Ali, ovo je samo jedan od načina na koji Šekspir oblikuje svoju dramaturgiju; na koji uvodi gledaoce u složeni istorijski svet u svojoj tragediji, u žanru koji je po svojim tipskim odlikama udaljen od svakodnevnosti. Ima u Šekspira, i to ne mnogo manje nego što je ovakvih ,paralelnih” početaka, drugih vrsta običnosti koje uglavnom preovlađuju u dramama koje su po svojoj dramaturgiji, to jest, načinu na koji se predstavlja dramska radnja, mnogo bliže ,registru običnog govora”. Svakodnevnost, ili the everyday, pojam je kojim se opisuje jedan od postupaka koje Šekspir koristi kada reaguje na prenaglašeni retorički stil u skoro svim svojim dramama. Svakodnevnost koja se u ovom radu ispituje kao odlika stilskog registra i jezičkog izraza suprotstavljena je neoklasicističkom stilu koji se posebno razvijao u dramskoj poeziji u šesnaestom i sedamnaestom veku.

Kao pojam i predmet kritike svakodnevnost se najčešće ispitivala u odnosu na svoje pripadanje materijalnoj istoriji i materijalnoj kulturi, i to posebno u likovnoj i primenjenoj umetnosti. Na primer, svakodnevnost je tema temeljnih studija o ranom flamanskom slikarstvu prepunom motiva iz svakodnevnog života ljudi. Kao takva, svakodnevnost je čest predmet predstavljanja u slikama flamanskih slikara, Brojgela (Bruegel), Vermera (Vermeer), i Halsa (Hals). Kritičari umetnosti posvetili su dosta pažnje tumačenju motiva i predmeta iz svakodnevnog života, predmeta koji u svojoj ukupnosti sačinjavaju svet naslikane ulice, kuhinje, krčme, trga, pijace, ili vašara; mesta koja se po svojim pojedinostima i celini razlikuju od sveta dvora, plemićke kuće, i vlastelinskog imanja i njegove pastoralne okoline. ${ }^{2}$ U nekim pak drugim istraživačkim kontekstima, tema svakodnevice, na primer u renensan-

KENT:I thought the King had more affected the Duke of Albany than Cornwall. GLOUCESTER: It did always seem so to us, but now in the division of the kingdoms it appears not which of the Dukes he values most; for equalities are so weighed that curiosity in neither can make choice of either's moiety. (1.1.1-6)

2 Na primer, ovo je tema istraživanja u knjigama De Bièvre and Shawe-Taylor i Buvelot. 
snoj Veneciji, obuhvata mikroistorijsku analizu pisanih tragova koje su iza sebe ostavili oni društveni slojevi - zanatlije, trgovci, ljudi od zanimanja koja nisu donosila ni previše novca ni mnogo slobodnog vremena - koje nije u prvi plan stavljala politička istorija. Glavne knjige prihoda i rashoda gradskih knjigovođa, te inventari iz domaćinstava - to su glavni predmeti istraživanja jedne nove studije o životu onih Venecijanaca koji nisu imali politički uticaj i čiji se kulturni životi nisu podudarali s njihovim zanimanjima. ${ }^{3}$ Kao termin, svakodnevica obuhvata više značenja u različitim konkretnim prostorima sveta od trinaestog do osamnaestog veka. U materijalnom smislu u kojem predmeti i prostori određuju svakodnevicu u šesnaestom i sedamnaestom veku, engleska komedija pretvara u jezički oblik pojedinosti onoga što vidimo u slikama flamanskih slikara svakodnevice, ili onoga o čemu čitamo u društvenoj istoriji o svakodnevici u renesansnoj Veneciji. Između suvereniteta umetnosti i drama, naravno, postoji razlika, koja se, između ostalog, tiče i načina na koji se svakodnevica predstavlja kao umetnički i retorički predmet u ovim medijima. U ovom radu, međutim, mene pojam svakodnevnosti zanima više kao filološka odlika drama koje su predstavljane u javnim pozorištima u Londonu. Na primeru nekoliko drama, zanima me da u nekoliko izdvojenih primera rasvetlim stilove kojima Šekspir predstavlja svakodnevnost u svojim dramama. Svakodnevnost nije drugo ime za realizam, koliko teorijsko opredeljenje i kritički pojam koji pomaže da se dramski stil shvata kao nešto što je poznato iz nekog drugog konteksta, a koji sada sa sobom nosi srodna ili drugačija značenja od onih koja se sa svakodnevnošću povezuju u materijalnoj istoriji.

U svojoj teoriji o svakodnevnosti, Anri Lefevr (Lefebvre), na primer, piše da svakodnevnost stvara „utisak poznatosti” (the impression offamiliarity) (1984: 53), pod čime on podrazumeva to da takvi trenuci svakodnevice čine da se stvarnost nikada ne iscrpi u organizovanim oblicima. Lefevr piše jednu uopštenu teoriju svakodnevnosti bez ulaženja u pojedinost toga kako bi se takva jedna teorija mogla koristiti u tumačenju svakodnevnosti i detalja njenog predstavljanja u književ-

3 Ovo je predmet ispitivanja Gwyneth Ross. 
nosti. U dramskoj književnosti, na primer, organizovani oblici na koje Lefevr aludira bile bi komedija i tragedija. Ovaj rad, koji je pregled jednog opsežnijeg istraživanja o stilu pisanja u dramama iz 90-ih godina XVI veka, pretpostavlja alternativni pristup analizi dramskog stila kao književnog postupka. Namera ovog istraživanja je da se proširi a ne umanji značaj tumačenja svakodnevnosti koja su već predstavljena u uticajnim istraživanjima iz materijalne istorije na različitim oblicima istoricističke kritike.

Kada Marko nožem udari o tanjir pun hrane i ubije muvu (3.1.53) u drami Tit Andronik; kada, u Komediji zabuna ${ }^{4}$, Dromio iz Sirakuze pita pogrešnog gospodara, Antifola iz Sirakuze, „Gospodaru, da odem i dignem Vaš prtljag iz broda?" (5.1.) $)^{5}$; kada Lans, iz komedije Dva viteza iz Verone, s podsmehom opisuje malog psa kao vevericu ("squirell"), kojeg su od njega navodno „ukrali...na trgu dželatovi dečaci” (4.5); i kada, u komediji Ukroćena zloća, Petručio zavodi Katarinu nudeći joj:
svileno odelo
I kape, i zlatno prstenje zacelo,
Narukvice, suknje nabrane i divne,
Šalove, lepeze, ćilibarske grivne,
Okovratnike, svu raskoš ne malu,
Biser i celu opremu ostalu. (4.3.)

poezija svakodnevnosti u ovim primerima prevazilazi samo značaj pesničke slike. Ovakve pesničke slike povezuju svet svakodnevnosti: od nehotičnog ubijanja muve do hvaljenja raskošnom garderobom i nakitom, do podsećanja na banalnost zaduženja koje imaju sluge, na svakodnevne radnje, ekonomski status, i ljudske reakcije u ekonomsko-materijalnom svetu drame, koji publiku podsećaju da antički Rim i savremena Italija nisu udaljeni od savremene Engleske gde su sve te

4 Živojin Simić i Sima Pandurović prevode naslove ove rane komedije samo kao Zabune, ali u dramskoj kritici i u različitim kritičkim izdanjima iz raznih perioda kritičkog priređivanja Šekspirovih dela, ova drama se navodi pod punim imenom The Comedy of Errors. Ja prilagođavam prevod naslova toj kritičko-uredničkoj praksi.

5 "Master, shall I fetch your stuff from shipboard" (5.1.410). 
radnje moguće. Ali, ove pesničke slike takođe pretvaraju različite vrste političkog sloja drame u tragediji i komediji u nešto što je samo naizgled bitno, dajući kasnoj elizabetanskoj tragediji i komediji drugačiji smisao. Ovaj otklon od političkog smisla do ,običnog kao beznačajnog”, kako slične primere opisuje Stenli Kavel (Cavell) (1996: 251) u dramama namenjenim za izvođenje za javna pozorišta proizvodi takav dramski momenat u kojem se jedan drugi smisao drame kao ličnog doživljavanja onoga što se odvija na sceni otkriva publici.

Moj izbor ove četiri najranije drame, drame koje je ili Šekspir sam, ili u koautorstvu s jednim ili dvojicom svojih savremenika napisao pre 1594. godine, kada je prestao da bude slobodan pisac i kada se potpuno posvetio radu profesionalnog dramskog pisca i poslovima koje su od njega zahtevale dužnosti suvlasnika u jednoj od dve poznate glumačke družine - Družine Lorda Komornika (The Lord Chamberlain's Men) - nije slučajan. Ove četiri drame su bile među najpopularnijim u pozorištima u najranijim godinama Šekspirovog dramskog stvaralaštva u Londonu. Njihova retorička raznovrsnost i povezanost sa savremenim i klasičnim modelima, ali i reagovanja na te modele, čine ih posebno zanimljivim predmetima rasprave o svakodnevnosti. Njihova jezička i izražajna energija i stilsko-konceptualna raznovrstnost suprotstavljaju se stilistici svakodnevnosti; u njima se tako ukrštaju dva vida stilskog izraza: retorički ukras i jezik običnosti kojim se opisuje svakodnevica.

Na početku poslednje decenije šesnaestog veka, neoklasicističko razumevanje tragedije kao vrste drame koja predstavlja pad herojskog lika i koja prikazuje snažne i često neobuzdane strasti preko raskošnog jezičkog stila kojim dominiraju retorički tropi i figure, te kao vrste drame koja je puna ubistava i prolivanja krvi, suprotstavlja se pojmu svakodnevnosti kao nečemu što je obično i nebitno, kako bi rekao Kavel. Tragedija predstavlja ljude koji se izdižu izvan običnog; koji su uhvaćeni u događaje kojima teško upravljaju, i koji ih lome; tragedija predstavlja sukob i izbor između slobode i sudbine. Nedavno je jedan kritičar rezimirao dugačku i složenu, i svakako ne pravolinijsku isto-

6 "the ordinary as uneventful". 
riju književne kritike o tragediji ovim recima: „U srcu tragedije, [kritika] nalazi ili nezaobilazni sudar između etičkih sila ili sukob između slobode i neophodnosti" (3). ${ }^{7}$ Međutim, kada svakodnevnost na tren zaustavi tok tragične rađe, kao što se to vidi na malom primeru iz Tita Andronika, takav dramski momenat ukazuje na to da je nasilje, koje je sastavni deo tragedije, jedno drugačije poimanje. Međutim, tragičnost nije samo dramska tradicija već i parodija tradicije tragičnog pisanja.

U trećem činu Tita Andronika nalazi se scena za koju neki od savremenih istraživača pretpostavljaju da ju je napisao Tomas Midlton (Thomas Middleton), a ne Šekspir, kako pretpostavljaju Tejlor i Duhejm (TAYLOR - DuhEJM 2017: 76-91). ${ }^{8}$ Danas je već prihvaćeno mišljenje da su koautori ove tragedije Šekspir i Džordž Pil (George Peele). Midltonov doprinos ovoj drami nije nešto neuobičajeno budući da je koautorstvo bilo česta praksa među dramatičarima. Midltonu se pripisuje autorstvo takozvane „scene s muvom” ("The Fly Scene”) koja govori o odnosu tragedije i svakodnevnice, u drami koja je možda najmanje od svih ranih drama određena svakodnevicom, budući da se radnja tragedije zbiva u stilizovanom predstavljanju antičkog Rima nakon što je pao pod najezdom varvarskih Gota. U trenutku kada Marko ubije muvu Tit Andronik objektivizuje smrt tako što je pretvara u parodiju herojske smrti kakvu nalazimo u tragediji kao dramskoj vrsti. Ova radnja takođe objektivizuje lik herojskog Rimljanina tako što je objekat ubistva muva. Moglo bi se reći da u ovom trenutku, drama relativizuje, i podsmeva se predstavljanju nasilja tako što meša tragediju s parodijom tragedije, tragičnog lika, i tragične radnje. Međutim, ovde se valja pozvati na Filipa Sidnija (Philip Sidney), pisca jedne od najuticajnijih teorija književnosti napisane u šesnaestom veku u Engleskoj, koji je napisao da je gnev „kratkotrajno ludilo”, kome kao primer služi to što ,Sofokle izvede Ajanta na pozornicu i prikaže ga

"At the heart of tragedy, [criticism of tragedy] locates either an unavoidable collision of ethical forces or a conflict between freedom and necessity."

8 Vidi, Taylor i Duhaime. 
kako ubija ili šiba ovce i volove, misleći da su grčki ratnici” $(48)^{9}$, tada nam ishod Markove radnje liči na nešto što je u duhu novog shvatanja tragedije u kasnom elizabetanskom periodu. U tragedijama pisanim u tom vremenu za potrebe repertoara u javnim pozorištima uzvišeno i prizemno mešaju se kako na nivou drame tako i na nivou stila. Midlton je tako dodao tragediji koju su napisala njegova dva savremenika scenu koja od tragedije pravi dramu o svakodnevnosti.

Nakon scenskog uputstva „MARKO udari nožem po zdeli” (3.2.), on objašnjava Titu, koji ga je upravo upitao „U šta udaraš, Marko, svojim nožem?" (3.2.), smireno, kao da je po sredi sasvim obična i očekivana radnja: "U ono što ubih, gospodaru, - muvu" (3.2.) Na to mu Tit Andronik odgovara:

Stidi se ubico, ubijaš mi srce;

Oči su moje presite nasilja.

Ne liči ubijanje nevinoga bića

Titovu bratu. Odlazi od mene;

Vidim da nisi za moje društvo ti. (3.2.)

A Marko Titu odgovara: „Vaj, gospodaru, ubih samo muvu” (3.2.). Takav jedan čin postaje povod za kratku ali napetu razmenu stihova o moralnoj opravdanosti ubistva jednog živog bića, makar to bila i muva, između dva brata. Ali, kada Marko konačno odgovori: „Oprosti brate, beše crna, ružna,/Slična caričinom crncu, te je ubih" (3.2.), ostaje da se pitamo zašto se Midlton toliko dugo zadržava na ovom detalju iz svakodnevice. Kritičarka Lori Magvajer (Maguire) tumači ovaj deo scene kao „ozbiljan udar na metaforičku konvenciju”. (2004: 174 $)^{10} \mathrm{Ja}$, međutim, predlažem da je ovde isto tako posredi i udar na retoričku konvenciju tragedije, u kojoj uzvišena retorika predstavlja stilski okvir za scene smrti u tragičnoj radnji uopšte. Ako Marko, a ne Tit Andronik, predstavlja glas nove tragedije, tragedije u kojoj se prepliću klasično

9 Preveo Veselin Kostić. U originalnom Sidnijevom tekstu: "Sophocles bring you Ajax on a stage, killing and whipping sheep and oxen, thinking them the army of Greeks" (1973: 108).

10 "a serious attack on metaphoric convention." 
i svakodnevno, tada je događanje onoga što je beznačajno (ubistvo muve) zapravo ono što je značajno jer je ono isto toliko važno koliko i umiranje ili ubijanje herojskog lika. U ovoj sceni vidimo primer pozorišta u kojem svakodnevnost briše razliku između heroja i nebitnog i slučajnog aktera unutar tragične drame. Običnost svakodnevnosti nas podseća na to da je ono što je beznačajno tragičan događaj.

Komedije, kako klasične tako i one neoklasične, pisane u kasnom elizabetanskom periodu, vrve od primera svakodnevnosti, zato što je komedija vrsta drame koja imitira i stalno kritički ispituje, između ostalog, jedan od osnovnih elemenata svakodnevnosti: ekonomski činilac u životu. Pošto se ekonomsko i erotsko značenje stalno prepliću, kako u novoj rimskoj komediji tako i u engleskoj neoklasičnoj komediji koja proizlazi iz rimske, ova dva elementa određuju značenje neoklasične komedije iz ranih 90-ih godina XVI veka. Nije slučajno da svakodnevnost dominira ovim komedijama. Engleska komedija ovog doba zaokupljena je, između ostalog, temama iz svakodnevnog života ljudi iz nižeg društvenog sloja. Svakodnevnost u komedijama suprotstavlja se kako mitološkom tako i alegorijskom značenju; ona podstiče na drugačiji način tumačenja klasične mitologije, namenjena je kao model za delovanje, ili pak kao upozorenje kako bi se izbeglo određeno ponašanje. U tom smislu i komedija, baš kao i tragedija, ima didaktičku funkciju, a svakodnevnost predstavlja jednu od značajnih stilskih alatki pomoću kojih se didakticizam komedije ugrađivao u svest publike javnog pozorišta, baš kao što je bila i izvor zadovoljstva koje proizlazi iz gledanja drame.

U ranoj komediji, Dva viteza iz Verone, može se videti kako Šekspir na jedinstven način pretvara mit u priču o svakodnevici. U džepu ogrtača koji je posudio od Valentina, Silvijin otac, Vojvoda je pronašao pismo koje je Valentin napisao njegovoj ćerki; ali u istom džepu je pronašao i uže koje je Valentin nameravao da upotrebi kako bi se popeo u spavaću sobu svoje izabranice. Vojvoda je upravo pročitao u pismu, „Silvija, noćas oslobodiću te” (3.1.), te nastavlja da komentariše sadržaj pisma: 
Ha, Faetone, - jer ti si Meropin sin -

Zar nebeska kola upravo ti bi

Da u ludosti toj zapališ svet?

Ti bi da zvezde sa neba dohvatiš,

Zato što one sjaju nad tobom! (3.1)

Sasvim je prikladno da otac jedne mlade žene doziva u sećanje klasičan mit koji se tiče odnosa oca i sina. To jest, Vojvoda publiku podseća na mit o Faetonu, sinu Helija i Okeanide, kojeg je Zevs usmrtio munjom kao kaznom za neodgovoran potez vožnje očevim četvoropregom koji mladić nije mogao da kontroliše, već se ili survao prema zemlji i pržio sve na njoj, ili se uzdizao toliko visoko od zemlje da se na njoj sve ledilo. Mit o Faetonu je bio sastavni deo školskih vežbi iz podražavanja klasične književnosti, čiji je cilj bio da se usvoji smisao mita kako bi se ovaj kasnije mogao pretvoriti u samostalni sastav, ali i kako bi se u tom postupku kreativnog pisanja vežbala upotreba retoričkih figura i tropa. Retorička pitanja, kojih je više u engleskom originalu nego u ovom prevodu na srpski ${ }^{11}$, kritički se odnose prema konvenciji podražavanja i verovatnoće, i navode publiku (a i čitaoce) da ovom mitu, kako ga predstavlja Vojvoda, priđu s kritičkom sumnjom. Ali, koja je izvorna pozadina jednog takvog predstavljanja mita u obliku niza retoričkih pitanja?

U knjizi Eikones (ili Imagines), koja je zbirka tumačenja i veoma rana rasprava iz istorije umetnosti, napisana na grčkom, nešto preko šezdeset napisa dvojice sofista, Filostrata (Philostratus), mlađeg i starijeg, mit o Faetontu se tumači tako što se kaže da on znači da u prirodi ima previše vatre. Međutim, ubrzo se nastavlja, kako bi se objasnilo da ,pesnici i slikari” u mitu o Faetontu vide „kočije i konje”, a u trenutku pada, nebo je pobesnelo. ${ }^{12}$ U Eikones, svakodnevnost je ekphrasis, to jest, retorički opis umetničkog dela umetnutog u književni tekst kao vinjeta. U ovom slučaju, svakodnevnost u takvom vizuelnom umetku povezuje se s realizmom opisa prirode u koju je pao

11 U originalu citamo sledeće: "And with thy daring folly burn the world?/Wilt thou reach stars because they shine on thee?" (3.1.155-6).

12 Citirano prema Loeb izdanju (1931: 4). 
mladić iz mita. Takav retorički postupak je nešto što je izvan mita, nešto što mitu i vizuelnom umetku u drami Dva viteza iz Verone daje posebnost. Klasični mit je postao svakodnevica koja publici daje priliku da didaktičnost mita prilagodi svakodnevnoj situaciji u kojoj renesansni otac ulaže mnogo retoričke energije kako bi sačuvao moralnu čistotu svoje ćerke.

U najranijim komedijama svakodnevnost se rečima preoblikuje i na druge načine. Lefevr piše da je „dvosmislenost kategorija svakodnevnog života, a verovatno i suštinska kategorija toga života” (1984: 4). ${ }^{13}$ Dvosmislenost koja je prema Lefevru u osnovi svakodnevnog života je isto tako i odlika Šekspirove upotrebe svakodnevnosti u dramama o svakodnevnom životu. U tim dramama, svakodnevnost je slikovito predstavljena kao život grada i prostora u gradu. Dramatizujući svakodnevnost na taj način, Sekspir ispituje i testira načine na koje tragedija i komedija kao dramske vrste predstavljaju svakodnevnost publici koja iz nje dolazi u javno pozorište, koje je i samo deo te svakodnevnosti. Komedija zabuna, koju je Šekspir napisao najverovatnije 1594. godine, kako pretpostavljaju najnoviji istraživači hronologije drama, Tejlor i Igan (Taylor - Egan 2017: 484-5ّ), prepuna je primera svakodnevnosti kao stilske kategorije. To bi se moglo očekivati od komedije koja se zbiva na trgovima i ulicama živog trgovačkog grada na istočnom Mediteranu, te unutar domaćinstava i kuća.

Kao tema kritike koja je posvećena istraživanju materijalizma u ranoj engleskoj drami, „kućevne stvari” (household stuff), ili pokućstvo, pripadaju raspravama o održavanju domaćinstva i „ekonomskog vođenja domaćinstva” (domestic economies). U tom smislu, Nataša Korda (Korda) se posvetila tumačenju odnosa između potrošačke robe, ljudskog roda, i vlasništva u predkapitalističkom periodu engleske društvene i kulturne istorije, osvrćući se naročito na različite vrste pretvaranja stvari u robu u ranoj modernoj Engleskoj. Dok Korda istražuje materijalna dobra kao indekse ljudskog roda u odnosu na pravne zakone i domaćinstvo, mene zanima stilski, to jest retorički

${ }^{13} \mathrm{U}$ engleskoj verziji originala, ovaj tekst glasi: "ambiguity is a category of everyday life, and perhaps an essential category [of that life]." 
registar kojim se o tim dobrima govori u dramama. Filološki pristup materijalističkom svetu rane komedije rasvetljava ne samo suštinu upotrebe svakodnevnosti, već pokazuje i na koji način je najranija faza još neoformljenog kapitalizma, u ranom modernom svetu, uticala na oblikovanje jezičkog stila drame u javnom, komercijalnom pozorištu. Kada se u ranoj komediji jezik strasti počeo sve dublje preplitati s jezikom kojim se pisalo o stvarima koje su do tada pripadale ili tržištu ili domaćinstvu, retorička drama 90-ih godina XVI veka je stvorila alternativni, autentičan, i moderan odgovor klasičnoj retorici svakodnevnosti, na koju, na primer, nailazimo u Plautovoj (Plautus) komediji Uže (Rudens) koja se do sada još nije povezivala s Komedijom zabuna, a koja je po svoj prilici ostavila trag na ovu Šekspirovu dramu.

Komedija zabuna je prepuna mesta iz svakodnevice koja povezujemo s bogatim i živim trgovačkim gradom na Mediteranu, gradu koji je u ovoj gradskoj komediji još dodatno zamišljen i kao haotično mesto pod uticajem magije. Dramska radnja i zaplet sele se s trga u kuhinju, na pijacu i u bordel; na kej i u spavaću sobu; a publika čuje o pomorskim putovanjima, popodnevnom dremanju, užetu, o zlatnoj ogrlici koju je napravio jedan zlatar, kao i o prstenu koji je vlasništvo jedne kurtizane. U Šekspirovom izvoru, Plautovoj komediji Menehmi, svakodnevnost predmeta, radnji, i bivstvovanja nisu prikazani do detalja do kojih su dramatizovani u Šekspirovoj komediji. Od Egeonovog dugačkog monologa kojim počinje drama, u kojem u detalj opisuje morsku plovidbu, buru, i razbijanje broda o stene (,dok su brodovi bili na pet milja / Od nas, naišli smo na ogromnu stenu / O koju smo se snažno udarili, / Da se naša katarka slomila / Nadvoje" [1.1]); do namere Antifola iz Sirakuze, koji će da ubije jedan sat koliko je ostalo do ručka tako što će „Gledati narod, videti trgovce, / Posmatrati zgrade, i vratiti se tad / U svoju krčmu, i spavati, jer sam / Ukočen, umoran od dugoga puta” (1.2.); pa onda do Dromija iz Efesa koji nadugačko razlaže o „,vremenu za ručak” (2.2.) i brine se da prase koje se peče ne zagori; te konačno do prve scene u četvrtom činu, u kojoj Andželo i Antifol iz Efesa razmenjuju svoje viđenje tržišta u Efesu - Komedija zabuna dramatizuje kontrast između pouzdanosti i nepouzdanosti koje se sučeljavaju u sudaru svakodnevnosti i sveta magije. U jednoj 
od upečatljivih scena, svakodnevnost dominira dramskom radnjom. Na sceni su Antifol iz Efesa i njegov sluga: treba kupiti uže, ali i lanac kod zlatara; razgovara se o iznosu novca, ,finoći zlata i ceni izrade” (4.2.), isplati rente (4.2.), ali i o ulju, balzamu, i prepečenici (4.1.), koju je Dromio iz Sirakuze nabavio pred put na more; a u ,sanduku pod turskim ćilimom" (4.1.) nalazi se kesa puna dukata, kaže Antifol, pa traži da se i ona pošalje, misleći da svog slugu (koji je zapravo prerušen sluga onog drugog Antifola) šalje svojoj gospi, a ne onoj koja pripada drugom Antifolu. Dramski likovi se zaokružuju u odnosu na opipljive predmete, pokret, i radnje, koji su sastavni deo svakodnevnog života i ritma grada. Istovremeno, svakodnevnost omogućava dramskim likovima da sačuvaju osećanje pripadanja stvarnom svetu grada i tržišta u trenucima kada se paganski svet magije sučeli sa svakodnevnim svetom tržišnog Efesa. Svakodnevnost se isto tako ogleda i u suprotnosti koja postoji između opasnosti gradskih ulica i udobnosti kućnog života. Na ovaj način se u komediji takođe raspravlja o odnosu između samoidentifikovanosti likova sa svetom gradske komedije i mistike paganskog sveta, koji se nalazi izvan sveta svakodnevnosti. Ako svaki pojedinac u publici u Šekspirovom pozorištu nije mogao u svakom trenutku dosledno da prati nijanse u upotrebi klasične retorike, retorika svakodnevnosti je omogućila da je svako mogao da prati dramu, iako razumevanje svega što je izdeklamovano na sceni nije bio preduslov razumevanja dramske poezije i proze u Šekspirovo vreme.

Dok retorika svakodnevnosti ispunjava scene koje se uglavnom odigravaju napolju, u gradu, dotle se scene svakodnevnosti u komediji Ukroćena zloća, kako naslov drame The Taming of the Shrew (1591) prevode Simić i Pandurović, uglavnom odvijaju u zatvorenim prostorima. Dok se Komedija zabuna usredsređuje na ono što nudi rano tržište, dotle se Ukroćena zloća uglavnom zanima za ono što čini domaćinstvo i na šta se nailazi u odajama kuća bogatih građana. Gremio se hvali bogatstvom i raskoši svoje kuće i gazdinstva, koji su:

Snabdevena...bogato srebrnim

Posuđem i zlatom; zatim lavorima

I krčazima za pranje njenih nežnih 
Ruku; zastori [tapiserije] su zidni svi iz Tira;

Kovčezi od slonovače puni

Novaca, a u onim kiparisnim

Stoje pokrivači, baldahini, ruho

Skupoceno i najbolje platno,

Turski jastučići biserom krašeni,

Zavese od mletačke zlatotkanine;

Imam kalajnog i bakarnog posuđa

I sve sto pripada kući i gazdinstvu.

A na mom poljskom dobru imam sto

Krava muzara i u stajama

Sto dvadeset debelih volova... (2.1.)

Šekspir dramatizuje svet svakodnevnosti kao svet modernosti usredsređen na estetiku opisivanja gazdinstva. Drama podiže na nivo poznatog ono što je obično tako što kućni predmeti koji su aktuelizovani nemetaforičkim jezikom bez ukrasa, objektivizuju na najbukvalniji način otklon od uzvišene retorike prepune stilskih figura. Pojedinosti od kojih je sačinjena svakodnevnost koriste da bi se njima podsmehu izvrgao ljubavnik, čime se nadugačko zabavljaju (a time zabavljaju i publiku) Lućencove sluge, Tranijo i Bjondelo. Bjondelo ovako najavljuje Petručijev dolazak na scenu:

Eto, Petručio dolazi u novom šeširu i starom korporanu; ima stare, triput prevrtane čakšire, poderane cipele, jedna s kopčom, a druga vezana vrpcom, star, zarđao mač... Njegova kljusina je iščašena kuka; ona ima staro moljcima izjedeno sedlo i dve različite uzengije... (3.2)

Petručijev lakej, „opremljen gotovo isto kao i kljuse” (3.2.), opisan je na sledeći način:

na jednoj mu nozi končana, a na drugoj dugačka vunena čarapa; a podvezao ih jednu crvenim a drugu plavim štofanim odsečkom. Na stari šešir, umesto pera, zadenuo pesmaricu od četrdest ljubavnih pesama. Pravo je čudovište u toj opremi, te i ne liči na hrišćanskog paža ni na gospodskog lakeja”. (3.2)

I jedan i drugi opis predstavljaju parodiju književnog tipa viteza lutalice iz viteško-herojske književnosti koja je, i preko dramskih i preko proznih romantičnih pripovesti (prose romance), bila poznata 
Šekspirovoj publici različitih društvenih slojeva i nivoa obrazovanja. Mešavina stila kojim se opisuje svakodnevnost, stila koji se odlikuje prepoznatljivim elementima iz romantičnih pripovesti, približava komediju svetu svakodnevnosti, ali je udaljava od klasicizma nove rimske komedije.

Stil kojim se svakodnevnost pretvara u predmet drame vuče korene iz engleske narodne tradicije usmenog pripovedanja kao poučne književnosti o ponašanju u braku, u glavnom zapletu. Međutim, u podzapletu ove komedije dramska poezija ne crpi izraz u repertoaru stilova i tema povezanih sa svakodnevnošću već u deklamatorskoj tradiciji klasične komedije Plauta i Terencija, ali preko drame Zamene (Supposes), Džordža Gaskojna (George Gascoigne). ${ }^{14}$ Ovakvo prilagođavanje registra klasične komedije registru engleske drame, a posebno svakodnevnosti u izrazu, podsticano je prilično rano u razvoju engleske drame u renesansi. Tako u predgovoru prvom izdanju engleskog prevoda Terencijeve komedije Andrija, štampane 1588, prevodilac Moris Kifin (Maurice Kyffin), piše: „Koristio sam se (što sam bliže mogao) najpoznatijim, čestim, i poznatim frazama iz običnog govora, kako bih iskazao autorova mišljenja, na način (kako ja mislim) koji se najbolje slagao zajedno s tim frazama." (1588: Ajv' ${ }^{15}$. Smisao Kifinovog tumačenja svog prevodilačkog principa je da engleski jezik koji koriste obični ljudi stvara „osećanje poznatog” (the sense offamiliarity), da se podsetimo Lefevra; a to osećanje poznatog, prepoznatljivog pa čak i prisnog, govora i stila čini da drame posmatramo kao deo svakodnevnosti. Način na koji prevod s latinskog na engleski, što je slučaj s Kifinom u odnosu na Terencijevu dramu koju on predstavlja engleskoj publici svoga doba, kako bi se premostio jaz koji razdvaja klasičnu od domaće drame, jeste ono sa čim Stenli Rozen (Stanley Rosen) povezuje svakodnevnost u pisanju.

${ }_{14}$ O izvorima za ovu dramu, opširnije piše Ann Thompson, 9-1\%.

${ }_{15}$ "I haue used (as neere as I could) the most knowen, vsuall, and familiar phrases in common speech, to expresse the authors meaning, as (to my thinking) best agreeing therewithal." 
Sa stanovišta dramske kritike i istoriografije, svakodnevnost otvara mogućnost da se otkrije jedan drugačiji kritički rečnik pomoću kojeg se tumači običnost, neukrašen govor, ili realizam filološke dimenzije materijalističke kritike. Šekspir koristi svakodnevnost u trenutku kada nagli razvoj pozorišne scene u Londonu stimuliše nagli razvoj drame u tim pozorištima. Stil, koji je uvek primer kulture i istorijskog trenutka, na šta je skretao pažnju još Ernst Gombrih (Ernst Gombrich), pišući o stilu u lepim umetnostima, pomaže nam da svakodnevnost kao dramski stil posmatramo kao primer istorijskog trenutka. Šekspirov stil svakodnevnosti ukazuje na to da je svakodnevnost bila odraz modernosti, zvukova i boja grada i njegovih pozorišta, a ponekad i odjek domaće kulturne tradicije, što je sve ukupno predstavljalo istovremeno i otklon od klasične dramske tradicije, ali i poseban način na koji se ta tradicija transformisala i prilagodila uslovima engleskog pozorišta i dramske književnosti ranih 90-ih godina XVI veka.

\section{IZVORI I CITIRANA LITERATURA}

CAvelL, Stanley. "The Ordinary as the Uneventful". The Cavell Reader, Stephen Mulhall (ed.). Oxford: Blackwell, 1996, 254-9.

De BiÈvre, Elisabeth. Dutch Art and Urban Cultures 1200-1700. New Haven and London: Yale University Press, 2015.

Korda, Natasha. Shakespeare's Domestic Economies: Gender and Property in Early Modern England. Philadelphia: University of Pennsylvania Press, 2002.

---. Working Subjects in Early Modern English Drama. London: Routledge, 2011.

---. Labors Lost: Women's Work and the Early Modern English Stage. Philadelphia: University of Pennsylvania Press, 2011.

Korda, Natasha, Jonathan GILL HaRris (eds.). Staged Properties in Early Modern Drama. Cambridge: Cambridge University Press, 2003.

Kostić, Veselin. Šekspirova dramaturgija. Beograd: Stubovi kulture, 2010.

KyfFin, Maurice, trans., Andria, trans. The First Comedie of Terence in English. London: T. E. for Thomas Woodcocke, 1588. 
LeveBre, Henri. Everyday Life in the Modern World, trans. Sacha Rabinovich. New Brunswick: Transactions Publishers, 1984.

---. Critique of Everyday Life. John Moore, trans. London and New York: Verso, 1991.

Maguire, Laurie E. Studying Shakespeare: A Guide to the Plays. Malden and Oxford: Blackwell, 2004.

Phinolstratus, Elder; Philostratus Younger. Imagines. Cambridge, Mass. i London: Harvard University Press, 1931.

Rosen, Stanley. The Ancients and the Moderns: Rethinking Modernity. New Haven and London: Yale University Press, 1989.

Ross, Gwyneth Sarah. Everyday Renaissances: The Quest for Cultural Legitimacy in Venice. Cambridge, Mass. and London: Harvard University Press, 2016.

ŠEKSPIR, Viljem. Dva viteza iz Verone. Zabune. Celokupna dela, knjiga prva. Borivoje Nedić i Živojin Simić (ur.). Beograd: BIGZ, Narodna knjiga, Nolit, Rad. 1978.

---. Ukroćena goropad. Celokupna dela, knjiga druga. Borivoje Nedić i Živojin Simić. Beograd: BIGZ, Narodna knjiga, Nolit, Rad, 1978.

---. Tit Andronik. Celokupna dela, knjiga treća. Borivoje Nedić i Živojin Simić. Beograd: BIGZ, Narodna knjiga, Nolit, Rad, 1978.

---. Kralj Lir. Celokupna dela, knjiga četvrta. Beograd: BIGZ, Narodna knjiga, Nolit, Rad, 1978.

ShakeSPEARe, William. The Two Gentlemen of Verona. Roger Warren (ed.). Oxford: Oxford University Press. 2008.

---. Titus Andronicus. Eugene M. Waith (ed.). Oxford: Oxford University Press, 2002.

---. The Comedy of Errors. Charles Whitworth (ed.). Oxford: Oxford University Press, 2002.

---. King Lear. Stanley Wells (ed.). Oxford: Oxford University Press, 2000.

---. The Taming of the Shrew. H. J. Oliver (ed.). Oxford: Oxford University Press, 1984.

Shawe-Taylor, Desmond i Quentin Buvelot. Masters of the Everyday: Dutch Artists in the Age of Vermeer. London: Royal Collection Trust. Mauritshuis: Mercatorfonds, 2015.

Sidney, Philip Sir. An Apology for Poetry. Geoffrey Shepherd (ed.). New York: Barnes and Noble and Manchester University Press, 1973.

---. Odbrana poezije Filipa Sidnija. Veselin Kostić (prev.). Beograd: Srpska akademija nauka i umetnosti, knjiga 39, 1989. 
Taylor, Gary, Doug Duhaime. "Who Wrote the Fly Scene (3.2) in Titus Andronicus". The New Oxford Shakespeare: Authorship Companion. Gary Taylor, Gabriel Egan (ed.). Oxford: Oxford University Press, 2017, 66-91.

Taylor, Gary, Gabriel Egan. "The Canon and Chronology". The New Oxford Shakespeare: Authorship Companion. Gary Taylor, Gabriel Egan (ed.). Oxford: Oxford University Press, 2017, 416-602.

Thompson, Ann. The Taming of the Shrew (ed.). Cambridge: Cambridge University Press, 1984.

Goran Stanivuković

\section{SHAKESPEARE AND THE EVERYDAY}

\section{Summary}

This essay explores several instances of the everyday in a selection of Shakespeare's plays, including Titus Andronicus, The Comedy of Errors, The Taming of the Shrew, and The Two Gentlemen of Verona. It explores the intersections between the everyday and dramatic genre, specifically the genres of comedy and tragedy as Shakespeare was reimagining them in the first half of the 1590s. The main argument of this short essay is that the everyday 'shrinks' the distance between comedy and tragedy as defined in classical dramatic terms. Underpinned by the theories of the everyday developed by Henry Lefebvre, Stanley Rosen, and Stanley Cavell, the everyday in this short essay is understood to be both a thematic and rhetorical (or stylistic) representation of the ordinary, uneventful, and quotidian intervention in the world and language which cuts through the poetics of tragedy and comedy. The everyday, therefore, is explored as a way in which the neoclassical drama of the public stage intervenes in the traditional, classical models of these two kinds of drama.

Keywords: the everyday, tragedy, comedy, the public stage, the first half of the 1590 s.

Univerzitet Sent Meri

Halifaks, Nova Škotska

Goran.Stanivukovic@smu.ca 